\title{
HEAVY-DUTY TRUCKS AND NEW ENGINE TECHNOLOGY: IMPACT ON FUEL CONSUMPTION, EMISSIONS AND TRIP COST
}

\author{
FRANS BAL \& JAAP M. VLEUGEL \\ RISSK \& Delft University of Technology, The Netherlands.
}

\begin{abstract}
Road transport offers important logistic benefits at a reasonable cost for producers and consumers, hence its large market share. But, its use of diesel or gas generates large volumes of $\mathrm{CO}_{2} \mathrm{NO}_{\mathrm{x}}$ and $\mathrm{PM}_{10}$ (among others). Higher emission standards and demand for greener transport call for alternatives. Literature analysis, a simulated Dutch-German road trip and a partial financial analysis are used to compare different engine-fuel combinations. Electricity from green sources removes these emissions. To stimulate full electric trucks (FET) several issues need to be addressed. First is creation of a large charging network. The Netherlands is much further with this than Germany. Affordability is another one. Operating and investment costs should at least equal those of non-FET to have comparable total cost of ownership (TCO) over the lifetime of a truck. With FET, investment costs are now much higher, which should be compensated by lower operating costs. The actual operating costs depend on many factors, but fuel costs and trip time are likely to rise if en-route recharging is needed. A more in-depth financial analysis is needed for more exact conclusions. Another issue is technical. Practice tests are needed to enhance the results of the simulation study. Hybrid diesel-electric and FET are already used in urban and regional transport. Regulation should also become tighter. Zero emission should become the norm. If these issues are successfully death with, then electric drive will become the mainstream technology. Technically, 2025 or 2030 seem feasible for large-scale production, which also lowers investment costs. With more electricity needed for transport, the supply of green electricity should grow strongly. Finally, the micro simulation is a modest example of the potential of the simulation model. Modeling of other corridors is underway, using one truck or a fleet of FET.

Keywords: barriers, electric, emissions, energy, heavy-duty trucks, policy, trip costs.
\end{abstract}

\section{INTRODUCTION}

Hardly any human activity can do without freight transport. It is already enormous in volume (see below) and also expanding rapidly, e.g. by more than 70\% between 1990 and 2015 in EU-25 (Fig. 1). This trend can be explained by interplay of demographic, economic, logistic and transport-technical factors:

- A rapidly growing world population, partially young, which corresponds with a high population growth and a growing demand for goods, services, infrastructure, buildings etc., which stimulates growth in GDP;

- Consumer demand has become globally sourced;

- Growing political and economic linkages between countries allow a division of labour and a global spread of manufacturing;

- A shift in industry structure; local manufacturing of mass-produced heavyweight products was largely transferred to low-wage countries [1]. High-wage countries became a major player in the service industry;

- Technical means, like containers, allow seamless transport on a world scale.

Road transport is dominating within and between (neighbouring) countries. More then six billion ton-kms were transported by road in the EU, USA, CIS, China and Japan in 2016. In 


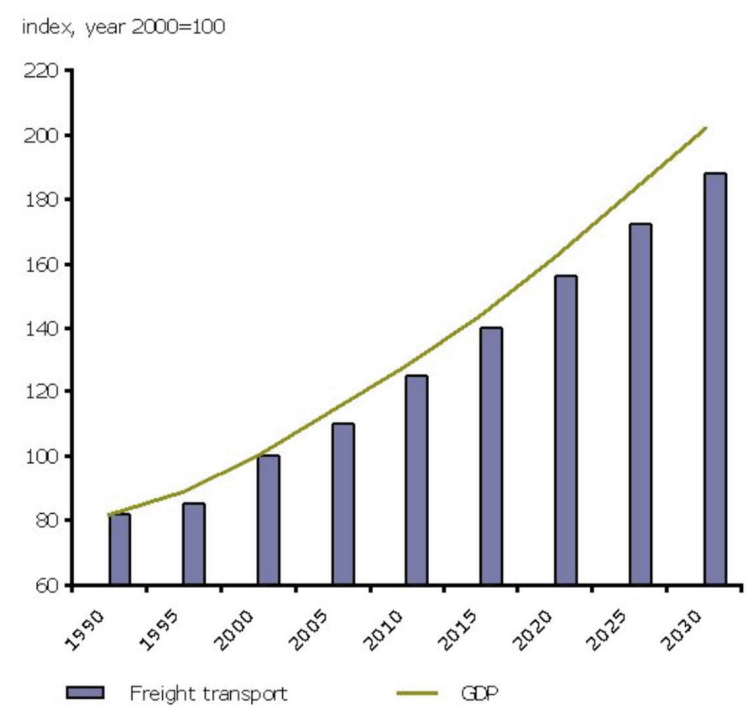

Figure 1: Growth of freight transport activity in EU-25 [2].

the EU, road freight transport had a market share of 50\% in 1970, which grew to $75 \%$ today [3]. These market shares differ per country, transport distance, goods category and the availability of efficient and cost-effective alternatives: barge, rail or pipeline.

Many of the consumer goods imported by developed countries are of the lightweight high value category. Overland transport mainly takes place by road [4]. Road transport offers door-to-door services via a high-density network to nearly every location, unlike barge or rail. It is very flexible (routes, time), practical to organize and faster than rail, although rising road congestion reduces this benefit. Short distance barge or rail services are rare, unless very large volumes are frequently transported [5]. Logistic service providers choose rail and barge if trucking is not economical or practical: for long distances (700 kms and upward) and large volumes. Trucks are still used to cover the pre- and end leg of such transport services, i.e. between intermodal terminals and producers or customers (warehouses, shops, consumers).

Road transport has a substantial share in final energy (fuel) consumption, $\mathrm{CO}_{2}$-emissions and air pollution. Since 1970 final global energy consumption of transport has grown exponentially (Fig. 2). Road transport accounts for more than $70 \%$ of it. Source [6] does not allow a split into passenger and freight transport, or a further subdivision into trucks, heavy and light duty vehicles. Trucks consumed 500 Mtoe (21 EJ) or $23 \%$ of the total energy consumption by the transport sector in the year 2005 [7]. It is unclear if this percentage has changed over time, but the number is indicative of its relative size.

This paper will deal with 2 EU-27 (28) countries: The Netherlands and Germany. Overall final energy consumption has decreased by $9,5 \%$ since the year 2000 (Table 1).

The growing final energy (fuel) consumption by transport is the result of a growing demand for transport that is only partially compensated by better fuel economy due to energy-saving technical development in vehicles and fuels [8]. As a result, transport has become the largest final energy consumer in the EU. This is a reason for serious concern, given the direct relationship between consumption of fossil fuels and $\mathrm{CO}_{2}$-emissions [9].

Many countries in the world have signed the Kyoto Protocol and its follow-ups, which call for a drastic reduction of GHG-emissions from fossil fuels [10]. There is also an OECD 

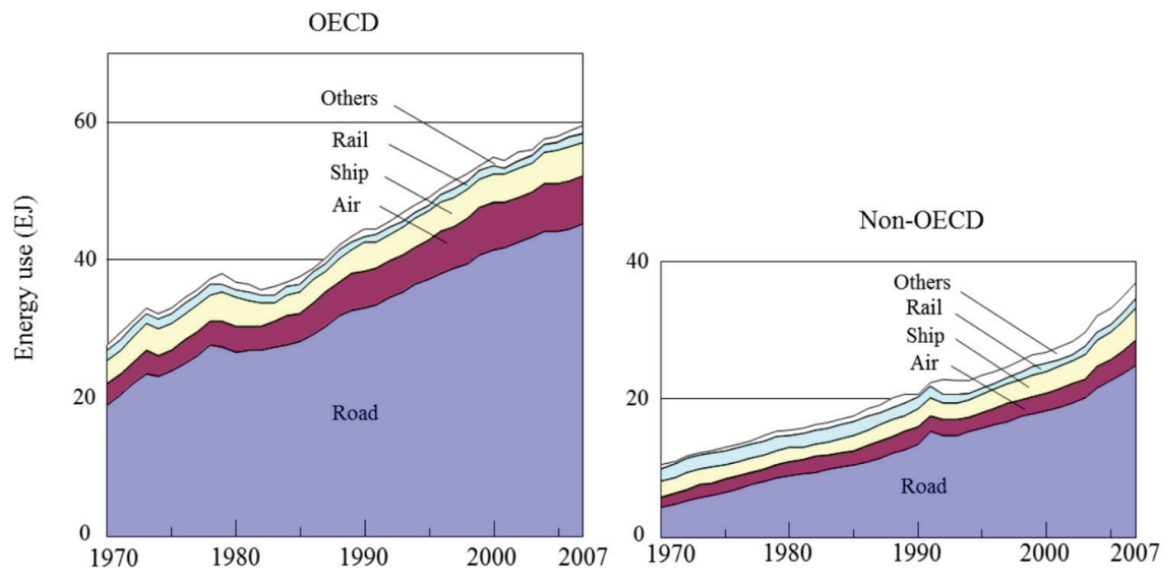

Figure 2: Transport energy use in OECD and non-OECD countries by modality [6].

Table 1: Final energy consumption in EU-27 countries in Mtoe [8].

\begin{tabular}{lrrrrr}
\hline & 2000 & $\%$ & 2015 & $\%$ & Change (\%) \\
\hline Transport & 345 & 29,8 & 359 & 32,4 & 8,7 \\
Industry & 333 & 28,7 & 271 & 24,5 & $-8,5$ \\
Residential & 311 & 26,8 & 293 & 26,5 & $-1,2$ \\
Services and non-specified & 142 & 12,2 & 159 & 14,4 & 18 \\
Agriculture & 28 & 2,3 & 23,4 & 2,1 & $-8,7$ \\
Total & 1159 & & 1105,4 & & $(-9,5)$ \\
\hline
\end{tabular}

initiative, which calls for green growth [11]. Is green growth of trucking a real option? The rising share of the transport sector in GHG-emissions suggests that the answer may be 'challenging to very doubtful', which illustrates the seriousness of this mega problem.

\section{RESEARCH GOAL, SCOPE AND QUESTIONS}

\subsection{Introduction}

The paper is part of a collaborative research into options to reduce energy consumption and emissions by passenger and freight transport as a step towards sustainable transport. It is a rewritten and extended version of [12]. Methodological details were added and the case study was enriched with a cost module to deepen the comparative analysis of alternative fuelengine combinations.

\subsection{Case study and scope}

A micro simulation experiment was developed, which allows estimating the impact of different engine-fuel combinations on fuel consumption and emissions. Micro refers to the 
decisions and behaviour of individual actors in a certain physical space, such as a simulated road network [13]. To reduce the complexity of modeling and subsequent analysis, some simplifications were inevitable.

The hypothetical central decision maker (agent) is a truck (fleet) owner at the brink of a truck (fleet) renewal decision. The paper does not deal with this decision from a financial perspective as in a business journal. It deals with the environmental impact and operational cost differences of alternative technical options to reduce truck fuel consumption. Then it becomes possible to shed more light on the 3P trade-off (people-planet-profit).

Costs matter in the very competitive truck market. Diesel cost has a share of around $20 \%$ in the cost price of trucking (labour counts for 50\%) in The Netherlands [14], hence less fuel per truck per road trip lowers the fuel bill, which contributes to a higher profit margin and gives a competitive advantage. For society, less fuel means less $\mathrm{CO}_{2}$-emissions. An even higher societal impact would result if (local) air pollution were reduced simultaneously.

A standard European heavy-duty road truck (40-44 metric tons) was taken as the technical platform in a simulated road trip in a high volume freight corridor between the Netherlands and its largest trading partner, Germany. This makes it a good example of similar corridor studies, which are underway. The simulated truck could use diesel or alternatives. The potential reductions in fuel consumption and emissions of $\mathrm{CO}_{2}, \mathrm{NO}_{\mathrm{x}}$ and $\mathrm{PM}_{10}$ could be estimated by comparing the emission of each fuel-engine combination. Of course, the time horizon should allow a partial upgrading or replacement of the truck fleet and fuel infrastructure in line with regular technical- or investment policies for such facilities.

Additional scoping was done because of the size of the paper. First, policy-making is briefly addressed. Second, this is a truck-only study. A partial modal shift to rail or barge is not in the scope. Third, logistics details are excluded.

The geographical region will be Western Europe, more in particular a frequently used corridor between two main freight nodes in the Netherlands and Germany. The on-going European harmonization effort gave European trucking companies common technical standards and in economic terms a level playing field. This allows European trucking companies to easily cross borders and use an extensive network of nearly identical fossil fuel stations.

\subsection{Research questions}

As the research dealt with technology (vehicles, fuels), environmental and economic impacts of using the fuels and the paper should also contain a future outlook, the following research questions are elaborated:

1. What is the global picture regarding final energy consumption and emissions of freight transport by road and why is this a major problem?

2. What alternatives fuel-engine combinations could heavy-duty truck manufacturers use to reduce fuel consumption and emissions of $\mathrm{CO}_{2}, \mathrm{NO}_{\mathrm{x}}$ and $\mathrm{PM}_{10}$ per truck?

3. What is the most promising alternative technology and why?

4. Do truck owners face a cost penalty when deploying this alternative?

5. What is needed to turn electric drive into a mainstream technology?

6. In what timeframe could this happen?

7. What could be the implications for fuel production? 


\section{RELEVANT TECHNOLOGY}

\subsection{Emission regulation}

Combustion of fossil fuels produces emissions of $\mathrm{NO}_{\mathrm{x}}, \mathrm{PM}, \mathrm{N}_{2} \mathrm{O}$ and $\mathrm{SO}_{2}$, and greenhouse gases $\left(\mathrm{CO}_{2}\right.$ or equivalent).

In the past decades exhaust emission standards have been introduced in most parts of the world. Europe has Euro emission standards for steady state and transient testing (for diesel and gas engines) [15]. New trucks have to comply with Euro 6.

A comparison with Euro 5 indicates a drastic reduction in most emission categories if all technologies do what they are supposed to and the trucks are regularly maintained. This is a major issue with international trucking companies, from foreign countries like Poland. Poland has taken over the trucking market from The Netherlands thanks to cheap labour and older, less well maintained, trucks. If caught by the police, these truckers can easily escape the fines, because the country of origin does not transfer the fines [16]. Since Euro 1 (1992) emissions of $\mathrm{CO}$ have been reduced by $66 \%$, HC by $89 \%$, NOx by $95 \%$ and PM by $97 \%$ per truck, at least on paper.

Producers of new trucks have achieved the Euro 6 emission standards. Modern truck engines combusting fossil fuels (diesel or gas) emit very small amounts of the before mentioned gases on highways [17]. The key technical challenge is to further reduce fuel consumption and emissions simultaneously, because a trade-off is no longer allowed. Another technical challenge lies in the reduction of emissions under less favourable conditions. On city roads, truck engines and gearboxes are used less efficiently; hence emissions are higher there.

\subsection{Technical and economic challenges}

The impact of tighter emission standards depends on many factors:

- Possibilities for modification of older trucks. There are after-market solutions for existing truck engines, in particular diesel particulate filters (DPF) that convert carbon into $\mathrm{CO}_{2}$. They need ultra low sulphur diesel and modern lubricants to prevent ash build-up, early servicing and performance degradation. A DPF may cost a few thousand Euros, but lasts well over $500.000 \mathrm{kms}$ if properly maintained [18];

- Fleet renewal. The biggest impact on fuel consumption and emissions should be expected from trucks designed for maximum fuel economy and emission reduction. The pace of fleet renewal depends on business-economic opportunities, depreciation practice and regulatory stimuli. It takes on average 7 or more years to replace a truck in The Netherlands and similar countries [19];

- Whether additional policy instruments are deployed, such as low emission zones in cities or along highways, which ban non-compliant trucks. People living in densely populated areas (city center) or near main roads and pedestrians appreciate a reduction in emissions and vehicle noise (e.g. due to electric trucks);

- Use of economic incentives, such as subsidies for automotive R\&D and differential taxation;

- Rising awareness in business that sustainable behaviour is inevitable and also pays off [20]. Companies with transport needs (shippers) may select a trucking company according to its 'green' performance and as such make their logistics more sustainable; 
- Fuel cost prices. Buying a more fuel-efficient truck and using it as fuel-efficient as possible does save money;

- The impact of exhaust gas emissions crucially depends on the efficiency of the exhaust cleaning system. This is not very effective if a truck is used only in cities [17], because a minimum temperature is needed to effectively burn particulates and clean the gases. This calls for active regeneration where fuel injection heats up the DPF [18].

Technical innovation enabled a major reduction in emissions and improved fuel efficiency (by new engines, tires, lighter materials, etc.) in the newest truck generation. Euro 6 regulates new trucks, not the older Euro classes, which are and more polluting. There is also no guarantee that the older Euro standards are being attained over time. With Euro 6 this is mandatory [15], although experience with the latest standards is of course limited. The pace of truck fleet replacement means that it may take at least a decade to achieve a measurable impact on the truck fleet using main roads. Truck emissions in cities remain a key problem, though.

The truck market in Europe is dominated by diesel from fossil origins. Could society and the environment benefit from a switch to alternatives? A case study will be used to deal with that question.

\section{METHODOLOGY AND CASE STUDY}

\subsection{Methodology}

The paper combines a literature analysis into technical development, fuel consumption and emission factors of trucks with transport economics.

A simulation model was built in MS@ Excel@. It was gradually developed over the past 34 years to carry out case studies (scenarios). It has been, in various stages of its development, used for quantitative analyses. Results of these analyses have been used in several earlier papers about the energy consumption and emissions of passenger and freight transport.

In this particular case, the purpose of modeling was to estimate the impact of different truck engine-fuel combinations and to evaluate these quantitative results. The model contains many levers, which can be used to model different truck uses. For each engine-fuel combination the model estimates the corresponding emissions of $\mathrm{CO}_{2}, \mathrm{NO}_{\mathrm{x}}$ and $\mathrm{PM}_{10}$ and the trip cost. The latter is based on the actual or estimated fuel price and value of time. The model consists of several modules, of which the most important ones are:

- A scenario data module. This allows to combine a trip scenario (origin-destination pair) with the mode of transport, engine-fuel pair and fuel details such as regular diesel and blends and alternatives like electricity and its source (grey, green);

- Tables with fuel consumption and emission factors (EF) by vehicle type or model;

- An output module to present the results of the simulation;

- In addition to the micro simulation module, there is also a macro simulation module, which is under development.

The model is very flexible. Parameters like route/distance, fuel efficiency/consumption, emission factors and engine-fuel configuration are changeable. 


\subsection{Case study: a trip scenario}

Everyday many trucks carry goods between the largest European port of Rotterdam and the German Rhein-Ruhr area. Freight transport between the Netherlands and Germany is among the largest in Europe. Hence, the choice of this example corridor is warranted.

Several assumptions were used in the scenario to simplify estimations:

- There are no intermediate breaks or fuel stops. This is a medium distance trip, which is assumed to be in the range of the latest highway legal electric trucks;

- There is no congestion.

The model considers three different types of links, viz. inner city roads, ring roads around a city and highways. A regular truck-trailer combination starts with a round-trip in Rotterdam's inner city and then follows the trip schedule of Table 2. Emissions are speed-dependent. Since the truck speed differs substantially per road section, emissions vary accordingly [21]. They will also differ per emission category $\left(\mathrm{CO}_{2}, \mathrm{NO}_{\mathrm{x}}, \mathrm{PM}_{10}\right)$. This is taken care of in the model.

\subsection{How to estimate the fuel consumption of trucks?}

It is important to distinguish between a theoretically optimal approach and a feasible practical approach. Theoretically, the fuel consumption of a heavy-duty truck is determined by many factors [22]:

- Technology: Vehicle specification, engine efficiency, rolling resistance, drag, brakes;

- Logistics: Supply chain characteristics, routing, vehicle use, speed;

- External factors: Driving speed, elevation, congestion, weather and driver behaviour.

Such a wide range of interrelated variables cannot be included in a standard model. Model practitioners usually apply a drastic simplification. This gives a choice between three methods [23]:

1. A direct and most reliable way is to use fuel bills or measured fuel consumption from a truck fleet owner's administration;

Table 2: Trip scenario for a one-way trip between Rotterdam (NL) and Duisburg (D).

\begin{tabular}{|c|c|c|c|}
\hline Link & Distance (kms) & Link speed & $\begin{array}{l}\text { TTW Fuel consumption } \\
(\mathrm{p} / \mathrm{ltr})\end{array}$ \\
\hline Rotterdam round trip (pick-up) & 3,5 & 20 & 1,33 \\
\hline Ring road & 2 & 70 & 0,64 \\
\hline Highways & 189 & 80 & 53,83 \\
\hline Duisburg ring road & 9,5 & 70 & 3,04 \\
\hline Inner city drop-off point & 2 & 20 & 0,76 \\
\hline Total & 206 & & 59,60 \\
\hline
\end{tabular}

Source: Own data and estimations. 
2. An alternative is to have a distance in vehicle kms and multiply this with average fuel consumption from public sources;

3. In case of outsourced transport, it is preferable to replace vehicle kms by logistics parameters like ton-kms and average transport distances. Average fuel consumption may vary considerably per logistic branch, load factor and \% of empty driving, though. This makes this method very imprecise.

It follows that when a source mentions a fuel/km ratio of, for instance 1:3-1:3.5 for a standard truck, that this is only informative if the basis for the calculations is transparent [24].

An actual truck fleet owner was not involved in the study and logistic details were excluded, hence method 2 was the best choice.

It was very demanding to find reliable public fuel consumption data and emission factors, in particular for alternative fuels. Technology is under development and competitive stress leads to secrecy by suppliers.

\subsection{Estimated trip emissions by fuel-engine combination}

The length and type of each link determine the time spent on it and thus the energy consumption per $\mathrm{km}$ and the value-of-time in minutes. The level of emissions is directly related to the energy consumption per link. Summation gives the estimated totals for energy use, emissions and value-of-time per link.

Estimations were made for the following engine-fuel combinations: FET, regular diesel, CNG and LNG/LBG (see Table 3). A Euro 6 truck-trailer combination uses around 59 liters of diesel to capture this distance. For the alternatives diesel-equivalent values were determined via regular energy conversion formulas.

Gas is mainly used for short distances and specific applications (buses, city logistics) in The Netherlands.

It becomes apparent that a shift from regular diesel to alternatives may have varying consequences for $\mathrm{CO}_{2}$-emissions. The real benefit is the reduction of $\mathrm{PM}_{10}$. Use of FET with green electricity from the grid ('electric highway' solution) will reduce the emissions due to (long haul) mobility drastically. The greener energy mix from the Germany grid (G/grey grid already leads to a $7 \% \mathrm{CO}_{2}$ reduction compared to the grey NL grid. The NL grid itself will become greener due to the rising import and local production of green energy. A greener grid means fewer emissions by electric vehicles powered by it.

Table 3: Estimated truck-trailer emissions.

\begin{tabular}{lccc}
\hline Type & $\mathrm{CO}_{2}{ }^{1)}$ & $\mathrm{NO}_{\mathrm{x}}{ }^{1)}$ & $\mathrm{PM}_{10}{ }^{1)}$ \\
\hline Regular diesel & 157944 & 656 & 154 \\
CNG (gas) & 140664 & No data & No data \\
LNG/LBG (gas) & 156480 & No data & No data \\
FET (grey) & 190436 & 157 & 13 \\
FET (green) ${ }^{2)}$ & 0 & 0 & 0 \\
\hline
\end{tabular}

Notes:

1) All emissions are in grams, based on tank-to-wheel (TTW).

2) If produced from green sources, and TTW only. 
4.5 Estimated trip cost by fuel-engine combination

Trip costs are a function of fuel cost and value of time. Fuel cost data was taken from [25]. Value of time was an average of four studies [26]: 44,48 Euros per hour. Fuel prices change over time, due to changes in oil prices and taxes. As diesel is the mainstream fuel, a few different diesel prices were used in the estimation.

The following formulas were taken from the model in order to prepare Table 4:

$$
\begin{gathered}
\mathrm{b}=\mathrm{ltr} / \mathrm{km} \cdot \mathrm{c} \\
\mathrm{e}=44,48 \cdot \mathrm{d} \\
\mathrm{f}=\mathrm{b}+\mathrm{e}
\end{gathered}
$$

\subsection{Evaluation and outlook}

The evaluation will first deal with the case study. First, the emission estimations are currently incomplete as regards emissions of gas-powered trucks. This means that the comparison of emissions is also incomplete. But, if fossil fuels are phased out, then this becomes of lower relevance.

Second, a few simplifying assumptions should be re-assessed. For instance, it is unclear if the latest FET can really be used under the varying conditions as described in the scenario. If a recharge is needed, then a fast recharge of 30 minutes, assuming an average VOT of $€ 44,48$ $\mathrm{p} / \mathrm{hr}$, will add another $€ 22,24$ to the generalized travel cost. Third, if the payload of FET is much less than that of a diesel or gas powered truck, then more FET are needed to ship the same payload. Economically, this makes FET non-competitive. Truck fleet owners will only invest large sums of money in new technology if this technology is widely available, reliable and affordable [27].

If one takes a broader perspective, then electric drive will become more important in transportation. Many researchers expect a growth in sales in the coming years [28]. This is reasonable given technical progress and more restrictive policies. In The Netherlands, the major truck owner's organization TLN even promotes this development; by saying that already by 2025 logistics in larger inner cities should only be carried out with zero emission vehicles. TLN also promotes a phasing out of biodiesel and biogas by 2030 [29]. This 'target' for electric trucks differs strongly from the current picture. By the end of 2017 there were

Table 4: Comparison of trip costs.

\begin{tabular}{lccccc}
\hline 206 kms (a) & $\begin{array}{c}\text { (b) Average } \\
\text { travel } \\
\text { cost / km }\end{array}$ & $\begin{array}{c}\text { (c) Fuel } \\
\text { price in } \\
\text { Euro / ltr }\end{array}$ & $\begin{array}{c}\text { (d) Travel } \\
\text { time in } \\
\text { hours (TT) }\end{array}$ & VOT (e) & $\begin{array}{c}\text { Generalized } \\
\text { travel cost (f) }\end{array}$ \\
\hline Regular diesel & 68,79 & 1,12 & 2.48 & 124,62 & 193,41 \\
Regular diesel & 76,77 & 1,25 & 2.48 & 124,62 & 201,40 \\
Regular diesel & 85,98 & 1,40 & 2.48 & 124,62 & 210,61 \\
CNG (gas) & 58,17 & 1,22 & 2.48 & 124,62 & 182,79 \\
LNG/LBG (gas) & 58,85 & 1,22 & 2.48 & 124,62 & 183,47 \\
FEV (green) & 107,22 & 0,34 & 2.48 & 124,62 & 231,65 \\
\hline
\end{tabular}


nearly 900 alternatively fueled trucks in The Netherlands: 500 with CNG, 300 with LNG and just 70 FET [27]. This iswhy [27] biodiesel and biogas are regarded as transition fuels before electrification could really take of (in Europe).

To remove these barriers a lot is necessary. Availability can be improved by the development of a dense standardized (heavy-duty) charging network covering all scale levels (local, regional, national, international). Reliability is a matter of large-scale production and adaptations in driver behaviour. Affordability covers operational (OPEX) as well as capital expenditures (CAPEX), both of which should be lowered substantially. Hesitance to invest is logical, because electric trucks are more expensive than diesel trucks and experience with maintenance is limited, although technically maintenance costs should be lower due to a smaller number of parts and removal of mechanical and hydraulic parts that need regular replacement. Economics is a real barrier, because trucking is for many years a loss making business in The Netherlands due to fierce competition from low wage countries and rising costs of fuel and labour [30].

\section{CONCLUSIONS}

Growth of trucking contributes to climate change, especially if the projected growth of trucking would be by diesel trucks. There are disruptive forces, most notably climate change mitigation policies, tightening emission and air quality standards and demand for green transport by shippers and customers. In response, truck manufacturers are developing alternative engine-fuel combinations.

From the analysis of literature and the case study by means of a simulation exercise, it becomes apparent that truck owners have alternatives for regular diesel: biodiesel (earlier paper), gas and electricity. Electricity from green sources totally removes harmful exhaust emissions. Its availability depends on the rollout of a charging network. The Netherlands is much further with e-mobility than Germany.

Affordability is a major barrier for the use of FET. Truck owners face a substantial cost penalty when deploying FET. This becomes even larger if en-route recharging is needed, because then the travel- and value-of-time costs rise, hence the generalized costs increase. Both operating and investment costs should become competitive to diesel or gas. Larger sales help to lower manufacturing cost and investment cost of electric trucks. Since we considered only part of the operating cost and none of the investment cost, a more in-depth financial analysis is necessary for a more definitive conclusion on this point.

In the model it was assumed that the currently available FET could be used for a regular trip like the modeled one. That has to be proven in practice. Hybrid diesel-electric trucks are already in use in cities and manufacturers are selling FET on a very small scale.

Electric drive will only become the mainstream technology if the FET and charging infrastructure are available (large-scale manufacturing, area covering charging network), reliable (experience with a larger fleets of FET) and affordable.

Regulation should also become tighter. Zero emission should become the de facto emission standard.

If these conditions are available, then a large-scale shift to electric trucking becomes feasible. Technically, 2025 or 2030 seem feasible for large-scale production.

With more electricity needed for transport, the supply of green electricity should grow strongly.

Finally, the micro simulation with one truck can be modified to estimate the environmental and economic impacts of using a fleet of trucks in this or another transport corridor. 


\section{REFERENCES}

[1] OECD, Decoupling the Environmental Impacts of Transport, www.oecd.org/greengrowth/greening-transport/37722729.pdf (accessed on 15 November, 2017).

[2] European Environment Agency, Freight transport activity growth for EU 25, www. eea.europa.eu/data-and-maps/figures/freight-transport-activity-growth-for-eu-25, Copenhagen, 2010 (accessed on 30 November, 2017).

[3] Eurostat, Energy, transport and environment indicators, 2016 edition, Luxembourg, 2016.

[4] In 2015, 3.4 bln. ton-kms were transported in EU-28, $50 \%$ went by road, $12 \%$ by rail, $4 \%$ by barge, $0,1 \%$ by air and $32.6 \%$ by sea. Figures vary per country and commodity type, Eurostat, Freight Transport Statistics - modal split, ec.europa.eu/eurostat/ statistics-explained/index.php/Freight_transport_statistics_-_modal_split (accessed on 23 November, 2017).

[5] Transporting export beer between Heineken's brewery in Zoeterwoude and the port of Rotterdam by barge saves $7.3 \mathrm{mln}$. truck kms (85\%) yearly. The engines of the barges (partially) use biofuel, www.ttm.nl/nieuws/heineken-shift-bier-van-truck-naar-binnenvaart/9006/ (accessed on 10 November, 2017).

[6] IIASA, Energy End-Use: Transport, www.iiasa.ac.at/web/home/research/FlagshipProjects/Global-Energy-Assessment/GEA_Chapter9.pdf (accessed on 11 November, 2017).

[7] Kojima, K. \& Ryan, L., Transport Energy Efficiency, IEA, Paris, 2010.

[8] Enerdata, Final energy consumption by sector in EU, http://www.odyssee-mure.eu/ publications/efficiency-by-sector/overview/final-energy-consumption-by-sector.htm, 2018 (accessed on 2 November, 2017).

[9] Ophardt, C., Global Warming, Carbon Dioxide and Fossil Fuels, Virtual Chembook, http://chemistry.elmhurst.edu/vchembook/globalwarmA4.html, 2003 (accessed on 2 November, 2017).

[10] UN, The Paris Agreement, unfccc.int/paris_agreement/items/9485.php (accessed on 4 November, 2017).

[11] OECD, Green Strategy Synthesis Report: Towards Green Growth, www.oecd.org, May 2011 (accessed on 26 November, 2017).

[12] Bal, F. \& Vleugel, J., "The Impact of hybrid engines on fuel consumption and emissions of heavy-duty trucks" WIT Transactions on Ecology and the Environment, 224, pp. 203-212, WIT Press: Southampton and Boston, 2017.

[13] This is not a traffic modeling study, but a policy analysis. Mitton, L., Sutherland, H. \& Weeks, W., Microsimulation Modelling for Policy Analysis, Challenges and innovations, Cambridge University Press, 2000.

[14] Resp. 18,5 \% (national) resp. 21,3\% (international). TLN, Transport in cijfers 2016, Zoetermeer.

[15] Dieselnet, EU: Heavy-duty truck and bus engines, www.dieselnet.com/standards/eu/ hd.php (accessed on 20 October, 2017).

[16] NOS.nl, Vuile buitenlandse trucks vaak niet beboet in milieuzones, 23-03-2018.

[17] Dijkhuizen, B., TNO: Euro 6 trucks sneller schoon dan nieuwe dieselauto's, Vakmedianet, 8 June 2015. ICCT, A technical summary of Euro 6/VI vehicle emission standards, www.theicct.org/sites/default/files/publications/ICCT Euro6/VI_briefing jun2016.pdf (accessed on 30 October, 2017). 
[18] Sturgess, S., Maintenance: Diesel particulate filters, HDT Heavy Duty Trucking, http:// www.truckinginfo.com/channel/maintenance/article/story/2009/05/diesel-particulatefilters.aspx, May 2009 (accessed on 3 October, 2017).

[19] ING Bank, Trucks en trailers, Truck- en trailermarkt in teken van optimalisatie, www.ing.nl/media/20150317\%20ING\%20Assetvie\%20Truck-\%20en\%20trailermarkt \%20in\%20teken\%20van\%20optimalisatie_tcm162-81579 .pdf (accessed on 3 November, 2017).

[20] The successful Lean \& Green program is an example in The Netherlands and Belgium, www.globalreporting.org/network/report-or-explain/campaign-forum-members/Pages/ Connekt---Lean-and-Green.aspx (accessed on 4 November, 2017).

[21] EPA, Average in-use emissions from heavy-duty trucks, EPA-F-08-027, October 2008.

[22] Odhams, A.M.C., Roebuck, R.L., Hunt, S.W. \& Cebon, D., Factors influencing the energy consumption of road freight transportation. Proceedings of the Institution of Mechanical Engineers, Part C: Journal of Mechanical Engineering Science, 224(9), 2004. https://doi.org/10.1243/09544062jmes2004

[23] VIL, Meten is weten - het berekenen van C2-emissies, http://vil.be/2013/ meten-isweten/\#, 2013 (accessed on 5 November, 2017).

[24] Bosman, P., Het gemiddeld gebruik van een vrachtauto, Google+, http://gemiddelden. nl/verbruik/gemiddeld-verbruik-van-een-vrachtauto, 2017 (accessed on 8 November, 2017).

[25] United Consumers, Actuele brandstofprijzen, dagelijkse update, www.unitedconsumers.com/tanken/ (accessed on 14 April, 2018).

[26] van Raemdonck, K. \& Macharis, C., Time valuation in traffic. Congestions costs, value of time \& lost vehicle hours, RA-MOW-2011-001, VUB Brussel, 2010.

[27] Eurostat, Greenhouse gas emission statistics, ec.europa.eu/eurostat/statistics-explained/ index.php/Greenhouse_gas_emission_statistics, 2017 (accessed on 2 November, 2017).

[28] Consultancy.nl, Inzet van overheid cruciaal bij energietransitie transportsector, 27 November, 2017 (accessed on 28 November, 2017). See also Navigant Research, Global Annual Sales of Electric Trucks are Expected to Reach 332,000 by 2026, www. navigantresearch.com/newsroom/global-annual-sales-of-electric-trucks-are-expectedto-reach-332000-by-2026 (accessed on 29 November, 2017).

[29] Logistiek.nl, TLN: in 2025 alle stadsdistributie elektrisch, www.logistiek.nl/distributie/nieuws/2017/09/tln-2025-alle-stadsdistributie-elektrisch-101157961?vakmedianetapprove-cookies $=1$ (accessed on 30 November, 2017).

[30] TLN, Transport in cijfers 2016, Zoetermeer. 